\title{
Kinetic Modeling of Vacuum Gas Oil Hydrotreatment using a Molecular Reconstruction Approach
}

\author{
N. Charon-Revellin' ${ }^{1}$ H. Dulot ${ }^{1}$, C. López-García ${ }^{1}$ and J. Jose ${ }^{2}$ \\ 1 IFP Energies nouvelles-Lyon, Rond-point de l'échangeur de Solaize, BP 3, 69360 Solaize - France \\ 2 Laboratoire des Sciences Analytiques, Université Claude Bernard Lyon I, 43 boulevard du 11 Novembre 1918, 69100 Villeurbanne - France \\ e-mail: nadege.charon@ifpenergiesnouvelles.fr - hugues.dulot@ifpenergiesnouvelles.fr - clementina.lopez-garcia@ifpenergiesnouvelles.fr \\ jacques.jose@univ-lyon 1.fr
}

\begin{abstract}
Résumé - Modélisation cinétique de l'hydrotraitement de distillats sous vide utilisant une approche de reconstruction moléculaire - Les Distillats Sous Vide (DSV) sont des coupes pétrolières lourdes (gamme de températures d'ébullition 350 à $550{ }^{\circ} \mathrm{C}$ ) qui peuvent être valorisées en carburants (essence, gazole) par craquage catalytique ou par hydrocraquage. Un hydrotraitement est requis avant ces procédés de conversion afin d'éliminer les impuretés du DSV. De cette manière, le procédé d'hydrotraitement permet d'attendre les spécifications environnementales (teneur en soufre) ainsi que de prévenir l'empoisonnement par les composés azotés des catalyseurs de conversion. De manière à pouvoir développer un modèle cinétique basé sur une description moléculaire précise des DSV, des outils analytiques innovant et des techniques de reconstruction moléculaire ont été utilisés dans ce travail. Un modèle cinétique de regroupement utilisant une représentation de type Langmuir-Hinshelwood a été développé pour l'hydrodésaromatisation, l'hydrodésulfuration et l'hydrodésazotation des DSV. Ce modèle de regroupement a été appliqué de manière satisfaisante à des données expérimentales de prétraitement de charge DSV et a été capable de prédire les évolutions de concentration des espèces aromatiques, azotées et soufrées.
\end{abstract}

\begin{abstract}
Kinetic Modeling of Vacuum Gas Oil Hydrotreatment using a Molecular Reconstruction Approach - Vacuum Gas Oils (VGO) are heavy petroleum cuts (boiling points ranging from 350 to $550^{\circ} \mathrm{C}$ ) that can be transformed into valuable fuels (gasolines, diesels) by fluid catalytic cracking or hydrocracking. Prior to these conversion processes, hydrotreating is required in order to eliminate the impurities in VGOs. The hydrotreatment process enables to meet the environmental specifications (total sulfur contents) and to prevent nitrogen poisoning of conversion catalysts. In order to develop a kinetic model based on an accurate VGOs molecular description, innovative analytical tools and molecular reconstruction techniques were used in this work. A lumped model using a Langmuir-Hinshelwood representation was developed for hydrodearomatization, hydrodesulfurization and hydrodenitrogenation of the VGO. This lumped model was successfully applied to the experimental feed pretreatment data and was able to predict evolution of concentration of the aromatics, nitrogen and sulfur species.
\end{abstract}




\section{INTRODUCTION}

In the present energetic framework, upgrading heavy petroleum cuts has become of major importance since the worldwide demand of energy is continuously increasing. Conversion of Vacuum Gas Oils into valuable transportation fuels by fluid catalytic cracking or hydrocracking represents a major issue for the refining industry. Vacuum Gas Oils (VGOs) are high boiling point petroleum cuts $\left(350-550^{\circ} \mathrm{C}\right)$ that contain large amounts of sulfur and nitrogen compounds. Since these heteroatomic compounds have a poisoning effect on conversion catalysts, Vacuum Gas Oils have to be upgraded by a hydrotreating stage before any further transformation processing. Among these chemical families, particular attention has to be paid to basic and non-basic nitrogen compounds (respectively acridine and carbazole-derivates) which are known to exhibit inhibitory or refractory behavior to all hydrotreating reactions depending on their basic or non-basic nature.

This work aims at developing a kinetic model of VGO hydrotreatment (HDT) taking into account hydrodearomatization, hydrodesulfurization as well as hydrodenitrogenation reactions. A particular attention has been paid to the difference in reactivity between the basic and non-basic nitrogen compounds. The challenge of this study comes from the lack of molecular analyses for Vacuum Gas Oils because of the very complex chemical composition of these samples. Only global properties such as density, elementary analysis or SAR analysis (Saturates, Aromatics, Resins) are generally available to characterize the chemical families present in VGO, and the few molecular analysis such as mass spectrometry are lacking boiling point information.

To overcome this difficulty, new analytical and numerical tools were developed to characterize and describe the compo- sition of Vacuum Gas Oils and their hydrotreated products. In the present study, the chemical information given by analytical characterizations and the molecular reconstruction of VGO feeds and hydrotreated products [1] was used for the kinetic modeling of this process. A lumped model using a Langmuir-Hinshelwood representation was developed for all hydrotreating reactions. Aromatic compounds are lumped into poly, penta, tetra, tri, di and mono-aromatic families and are transformed by reversible hydrogenation reactions. For the sulfur and nitrogen compounds, the reaction scheme considers a two-step mechanism involving hydrogenation and hydrogenolysis reactions. The model parameter estimation was based on experiments that were carried out on a pilot unit using an industrial sulfided NiMo/alumina catalyst and real VGO feedstocks. This lumped model was successfully applied to these experimental feed pretreatment data and was able to predict evolution of concentration of the aromatics, nitrogen and sulfur species.

\section{EXPERIMENTAL SECTION}

\subsection{Materials and Standards}

Eleven Vacuum Gas Oil feedstocks were used in this work. All samples were provided by IFP Energies nouvelles-Lyon. The virgin VGOs were obtained from crude oils from different geographical areas and the conversion VGOs from various refining processes (Tab. 1). To comply with product specifications and to remove the nitrogen-containing inhibitors, a hydrotreating stage was performed on these Vacuum Gas Oils. The samples referred to as A to $\mathrm{K}$ were hydrotreated over a sulfided $\mathrm{NiMo} /$ alumina catalyst under the following experimental conditions: $375-400^{\circ} \mathrm{C}, 40-140 \mathrm{bar}$

TABLE 1

Physico-chemical properties of Vacuum Gas Oils

\begin{tabular}{|c|c|c|c|c|c|c|}
\hline VGO sample & Description & $\begin{array}{c}\text { Density } \\
@ 15^{\circ} \mathrm{C} \mathrm{(-)}\end{array}$ & $\begin{array}{l}\text { Boiling point } \\
\text { interval }\left({ }^{\circ} \mathrm{C}\right)\end{array}$ & $\begin{array}{l}\text { S content } \\
\text { (wt } \%)\end{array}$ & $\begin{array}{l}\text { N content } \\
(\text { wt ppm N) }\end{array}$ & $\begin{array}{l}\text { Basic N content } \\
(\text { wt ppm N) }\end{array}$ \\
\hline VGO A & African straight run VGO & 0.9424 & $315-601$ & 0.42 & 1655 & 701 \\
\hline VGO B & Middle-East straight run VGO & 0.9414 & $333-619$ & 2.92 & 1357 & 427 \\
\hline VGO C & Mixture of a VGO and a heavy cycle oil & 0.9442 & $262-619$ & 2.63 & 1945 & 535 \\
\hline VGO D & African straight run VGO & 0.9425 & $257-437$ & 0.46 & 1450 & 736 \\
\hline VGO E & Mixture of a VGO and a deasphalted oil & 0.9457 & $334-675$ & 2.79 & 1325 & 350 \\
\hline VGO F & Middle-East straight run VGO & 0.9270 & $316-587$ & 2.03 & 1528 & 440 \\
\hline VGO G & Mixture of VGOs & 0.9367 & $357-583$ & 2.69 & 940 & 277 \\
\hline VGO H & Hydrocracked atmospheric residue & 0.9547 & $317-583$ & 0.58 & 3765 & 1071 \\
\hline VGO I & Middle-East straight run VGO & 0.9434 & $329-614$ & 3.08 & 1154 & 374 \\
\hline VGO J & Hydrocracked atmospheric residue & 0.9531 & $332-574$ & 1.31 & 2042 & 763 \\
\hline VGO K & South America straight run VGO & 0.9811 & $327-572$ & 3.44 & 2913 & 813 \\
\hline
\end{tabular}


(total pressure) with a contact time of 0.5-2 hours. The resulting heavy fractions $\left(375^{\circ} \mathrm{C}+\right)$ of hydrotreated VGOs were also studied in this work.

\subsection{Instrumentation}

Vacuum Gas Oils were analyzed using an Agilent HP6890 gas chromatograph equipped with a DB1HT (high temperature) capillary column (length: $30 \mathrm{~m}$, internal diameter: $0.32 \mathrm{~mm}$, film thickness: $0.1 \mu \mathrm{m})$. A novel hyphenated technique was developed to obtain a multi-element $(\mathrm{C}, \mathrm{H}, \mathrm{S}$ and $\mathrm{N})$ analysis of VGOs. The gas chromatograph column output was connected to both an Agilent G2350 Atomic Emission Detector (AED) and an Antek 7090 Nitrogen Chemiluminescence Detector (NCD). The AED and NCD detectors work under different pressure conditions, therefore two transfer lines of different lengths were inserted between the GC column output and each detector. This GC-AED/NCD information was used to calculate multi-element $(\mathrm{C}, \mathrm{H}, \mathrm{S}$ and $\mathrm{N})$ simulated distillation curves of Vacuum Gas Oils.

In this work, a new solid-phase extraction method was developed to separate the basic and non-basic nitrogencontaining compounds that are present in Vacuum Gas Oils. An Amberlyst 15 ion-exchange resin was used to fractionate the petroleum cuts using first ethanol to elute non-basic nitrogen compounds. Then, basic nitrogen species were desorbed from the resin using a dichloromethane/ammonium mixture prior to water addition and liquid/liquid extraction with dichloromethane. A "Non-basic fraction" and a "Basic fraction" resulted from each VGO separation (except for VGO G which was not submitted to the extraction). The NF M07-058-92 method was used to determine the total nitrogen content of each fraction while the basic nitrogen content was measured according to a potentiometric method.

\section{RESULTS AND DISCUSSION}

\subsection{Analytical Characterization of Vacuum Gas Oils and Hydrotreated Products}

Analyzing heavy petroleum cuts such as Vacuum Gas Oils represents a real challenge. These petroleum cuts are very complex chemical mixtures of hydrocarbons, sulfur and nitrogen-containing compounds which are distributed over a wide range of boiling points and polarities. As a consequence, there is a lack of detailed molecular characterization data for these industrial petroleum cuts. Regarding nitrogen analyses, only the total and basic contents are the nitrogen data that are usually available for Vacuum Gas Oils.

In a previous study [1,2], the authors have demonstrated that a Nitrogen Chemiluminescence Detector (NCD) is a sensitive and selective detector that can be successfully used to analyze nitrogen boiling point profiles of VGOs and hydrotreated $375^{\circ} \mathrm{C}+$ cuts. Since the NCD is a nitrogen specific detector, the boiling point calibration of GC-NCD chromatograms using normal paraffins is not directly possible. To circumvent this obstacle, an innovative GC-AED/NCD system was developed. In this hyphenated technique, the C, $\mathrm{H}$ and $\mathrm{S}$ signals were provided by the AED detector, while the nitrogen profile was simultaneously analyzed by the NCD detector. The main advantage of this system is that it provides by means of a single analysis the multi-element $\mathrm{C}$, $\mathrm{H}, \mathrm{S}$ and $\mathrm{N}$ simulated distillation curves. This information is directly related to the boiling point repartition of hydrocarbons, sulfur and nitrogen-containing compounds in Vacuum Gas Oils.

Figures 1 and 2 illustrate the sulfur and nitrogen simulated distillation curves of Vacuum Gas Oils (VGOs A to K). In most of the cases, less than $10 \%$ of the heteroatomic compounds have boiling points lower than $350^{\circ} \mathrm{C}$. Heavy compounds $\left(\mathrm{BP}>550^{\circ} \mathrm{C}\right)$ represent less than $20 \%$ of the sulfur and nitrogen contents of Vacuum Gas Oils (except for samples $\mathrm{D}, \mathrm{E}$ and $\mathrm{H}$ ). The sulfur and nitrogen boiling point profiles obtained from the GC-AED/NCD system provide very useful information of the heteroatomic distribution of Vacuum Gas Oils.

One of the goals of this study is to better understand reactivity of the basic and non-basic nitrogen compounds under industrial hydrotreatment conditions. To achieve this goal, the boiling point distributions of the acridine and carbazole-derivates must be determined. The nitrogen compounds belonging to both basic and non-basic families consist of a huge number of isomers distributed over the entire boiling range of the cut, however. Therefore, the GC-NCD chromatograms of VGOs are humped signals with no discrete peaks [1]. As a consequence of this lack of resolution, the basic and non-basic nitrogen-containing compounds can not be directly distinguished nor quantified with the GC-NCD chromatograms. For this reason, the two nitrogen families need to be separated prior to GC-AED/NCD analysis. Separation of basic and non-basic nitrogen-containing compounds is difficult to carry out because of the low contents of nitrogen in Vacuum Gas Oils ( $<4000 \mathrm{wt}$ ppm) and the predominant presence of a complex hydrocarbon matrix. Solid phase extraction methods based on the use of silica [3-10], alumina [11, 12] or ionexchange resin $[13,15]$ as well as liquid/liquid extractions $[6,7,11,15-18]$ were described in literature to separate and highly concentrate the basic and non-basic nitrogen species present in petroleum cuts. Nevertheless, these methods are time-consuming, involve a large number of intermediate steps and present in most cases issues with lack of selectivity and/or nitrogen recovery. The use of a NCD detector as a selective and sensitive nitrogen detector enables to overcome the difficulties brought about the nitrogen concentration steps. Hence, a relatively simple solid phase extraction method was developed in this work (Experimental Section). This technique was based on an ion-exchange resin and 


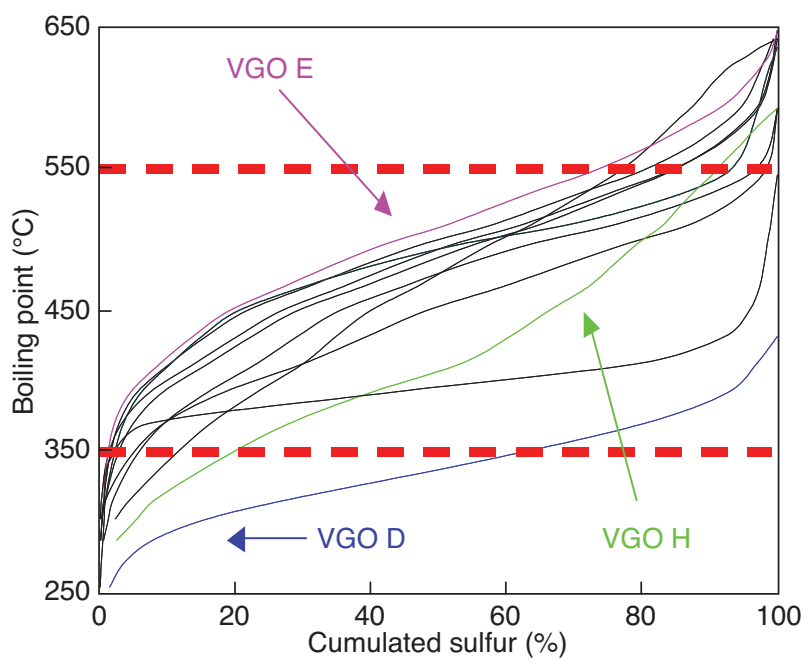

Figure 1

Sulfur simulated distillation curves of Vacuum Gas Oils.

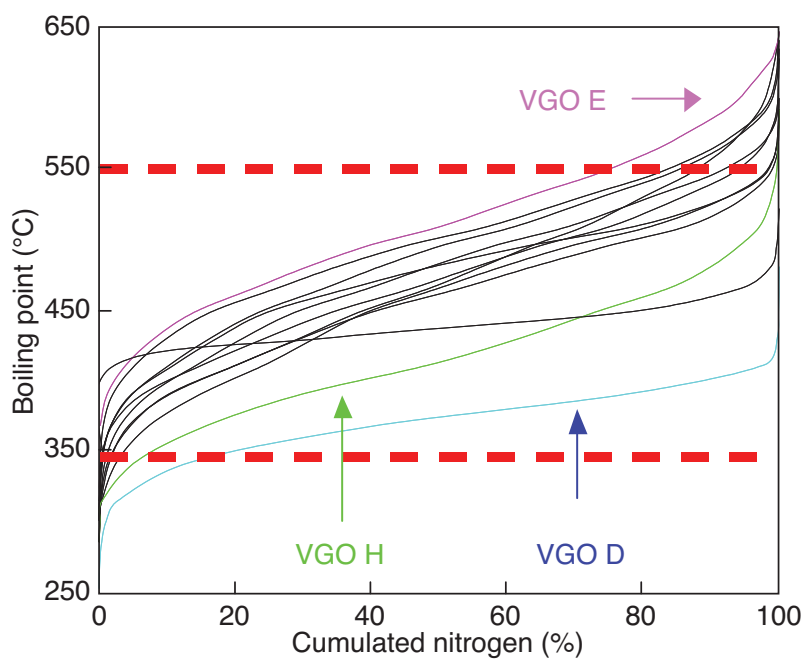

Figure 2

Nitrogen simulated distillation curves of Vacuum Gas Oils.

enables the fractionation of Vacuum Gas Oils into a "NonBasic fraction" and a "Basic fraction". Both quantitative and selective aspects of the method were examined.

Since the method must be quantitative and selective, the total and basic nitrogen contents of each fraction were measured by elemental analyses and the recovery yields of total, basic and non-basic nitrogen contents were estimated. Regarding the total nitrogen content, for most of the cases the recovery was estimated at minimum $80 \%$ (Fig. 3). Recovery yields of $80 \%$ minimum were also observed for basic nitrogen content (for $90 \%$ of the VGOs) and for non-basic nitrogen content (for $70 \%$ of the VGOs). These results show that minor losses of nitrogen containing-compounds occur during the separation of basic and non-basic nitrogen species and that these losses are not a function of the type of sample neither of the total nitrogen content initially contained in the Vacuum Gas Oils.

Figure 4 shows that the "Non-basic fractions" contained a minimum of $90 \%$ of non-basic nitrogen compounds. Similarly, at least $75 \%$ of the "Basic fractions" was effectively composed of basic nitrogen-containing compounds. These results show that the solid-phase extraction method developed in this work enables a quantitative and selective separation of the basic and non-basic nitrogen compounds that are present in Vacuum Gas Oils.

The "Basic" and "Non-basic" fractions resulting from the ion-exchange separations were then analyzed using the GC-AED/NCD technique. For almost all Vacuum Gas Oils, the simulated distillation curves show that basic nitrogencontaining compounds have higher boiling points than nonbasic nitrogen compounds, except for the samples A and D. As a conclusion of the analytical work, new experimental data on the boiling point repartition of basic and non-basic nitrogen species in Vacuum Gas Oils were provided by both the solid-phase extraction method and the hyphenated GC-AED/NCD technique.

\subsection{Molecular Reconstruction of Vacuum Gas Oils and Hydrotreated Products}

Despite the fact that the analytical tools developed in this study provide very useful information on the heteroatomic compounds, molecular analyses of Vacuum Gas Oils are not directly available. To overcome this lack of detailed information, a numerical method called "molecular reconstruction" has been developed and applied to Vacuum Gas Oil cuts $[1,19]$. This approach aims at representing a petroleum fraction via a mixture of molecules which are carefully optimized so that the physico-chemical properties of the mixture fit the "global" analyses of the industrial cut. The molecular reconstruction method used in this work consists of a two-step algorithm that couples stochastic reconstruction and entropy maximization approaches [20-26] (Fig. 5).

First, stochastic reconstruction is based on the hypothesis that a molecule can be described by a set of structural attributes (polycyclic cores, rings, chains, etc.), each of them following a statistical distribution. A random sampling of those structural attributes by a Monte Carlo method enables the selection of the type and number of each structural block to create a molecule (Tab. 2). The stochastic reconstruction creates an equimolar mixture of saturates, aromatics, sulfur- and nitrogen-containing compounds. Chemical knowledge can be introduced during stochastic reconstruction as the molecule construction scheme and the statistical distributions of structural attributes are defined by the user. 


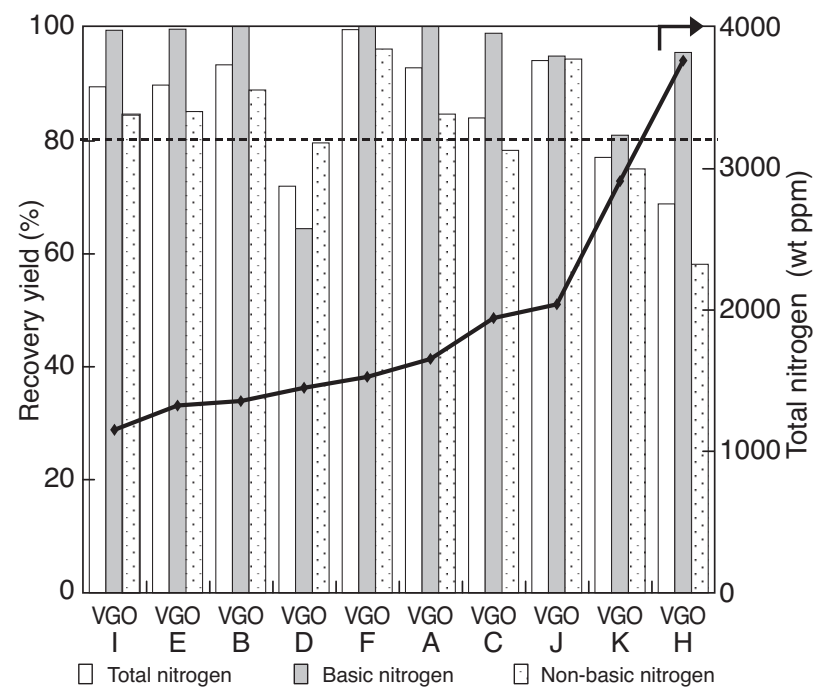

Figure 3

Recovery yields of the basic/non-basic nitrogen separation method for VGOs.

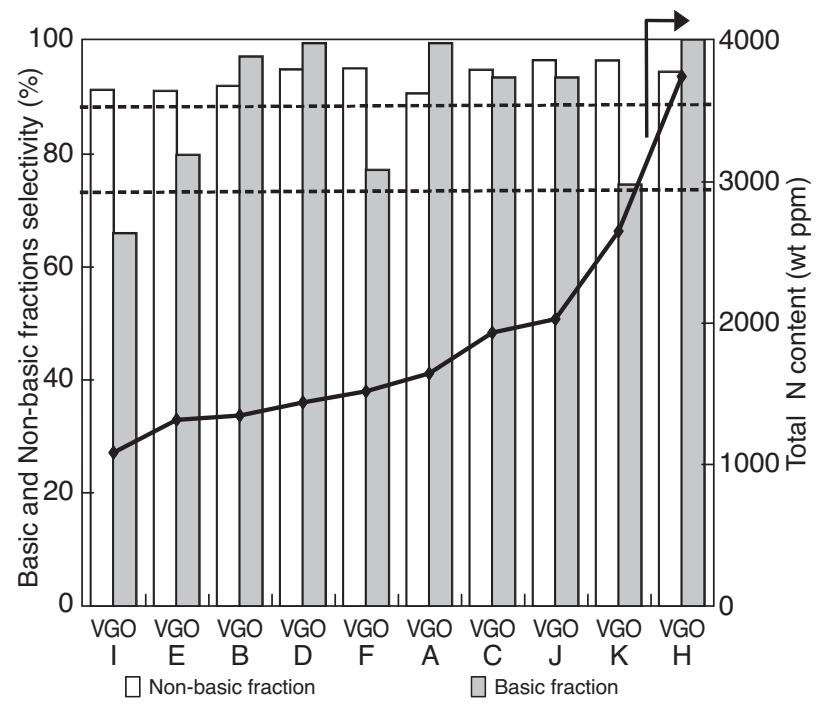

Figure 4

Selectivity of the basic/non-basic nitrogen separation method for VGOs.

Stochastic reconstruction

Creation of $n$ molecules

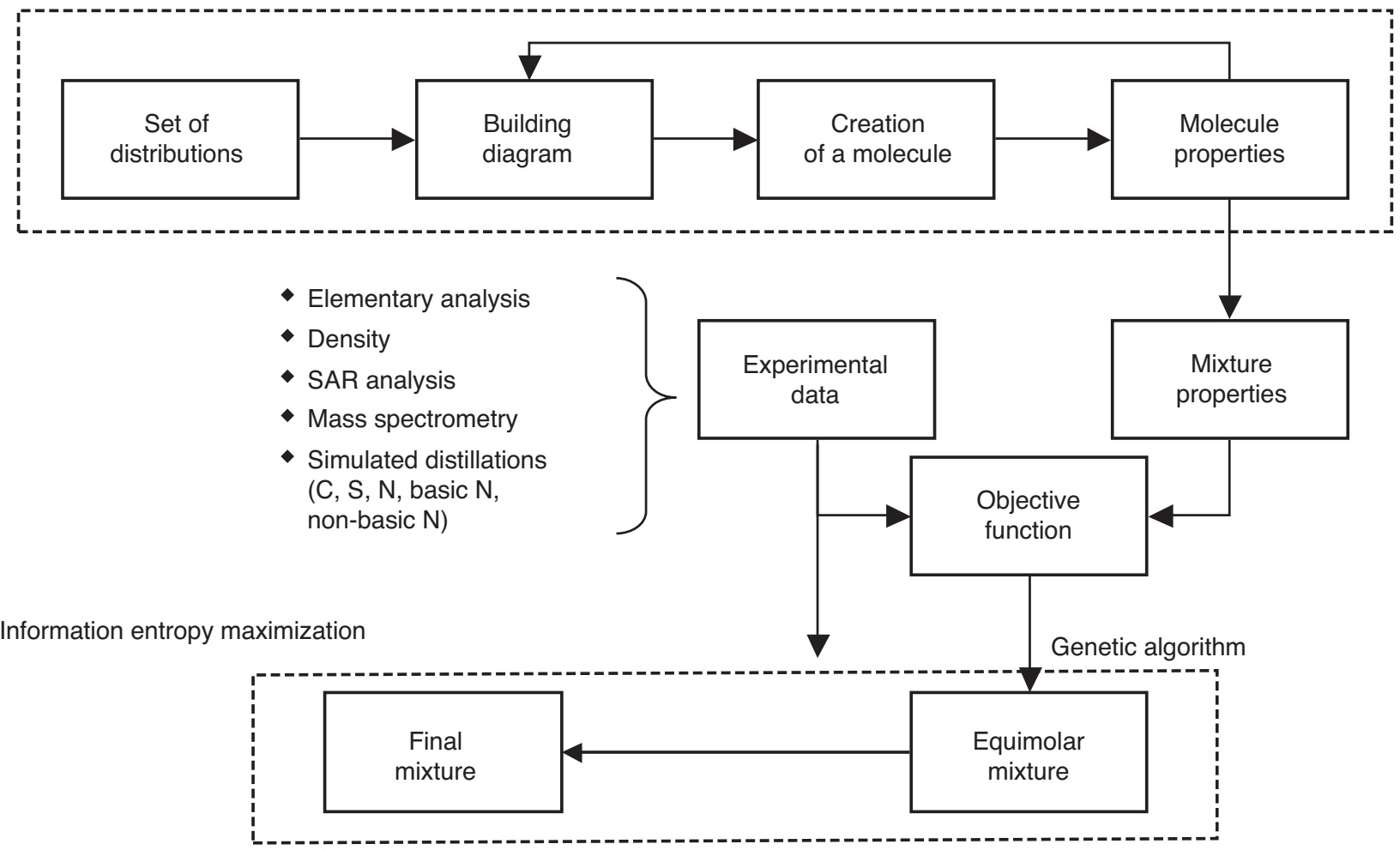

Figure 5

General scheme of the Vacuum Gas Oil molecular reconstruction method. 
TABLE 2

Structural attributes used in the stochastic reconstruction algorithm

\begin{tabular}{l|c}
\hline Structural attribute & Statistical distribution \\
\hline Number of polycyclic cores & Histogram \\
\hline Number of total rings per core & Gamma \\
\hline Type of molecule (naphthenic or aromatic) & Histogram \\
\hline Number of aromatic rings & Exponential \\
\hline Number of thiophenic rings & Histogram \\
\hline Number of pyrrolytic rings & Histogram \\
\hline Number of pyridinic rings & Histogram \\
\hline Side chain on $\mathrm{CH}_{2}$ & Histogram \\
\hline Length of a side chain & Gamma \\
\hline Length of a paraffin & Gamma \\
\hline Sulfur or amine on a side chain & Histogram \\
\hline
\end{tabular}
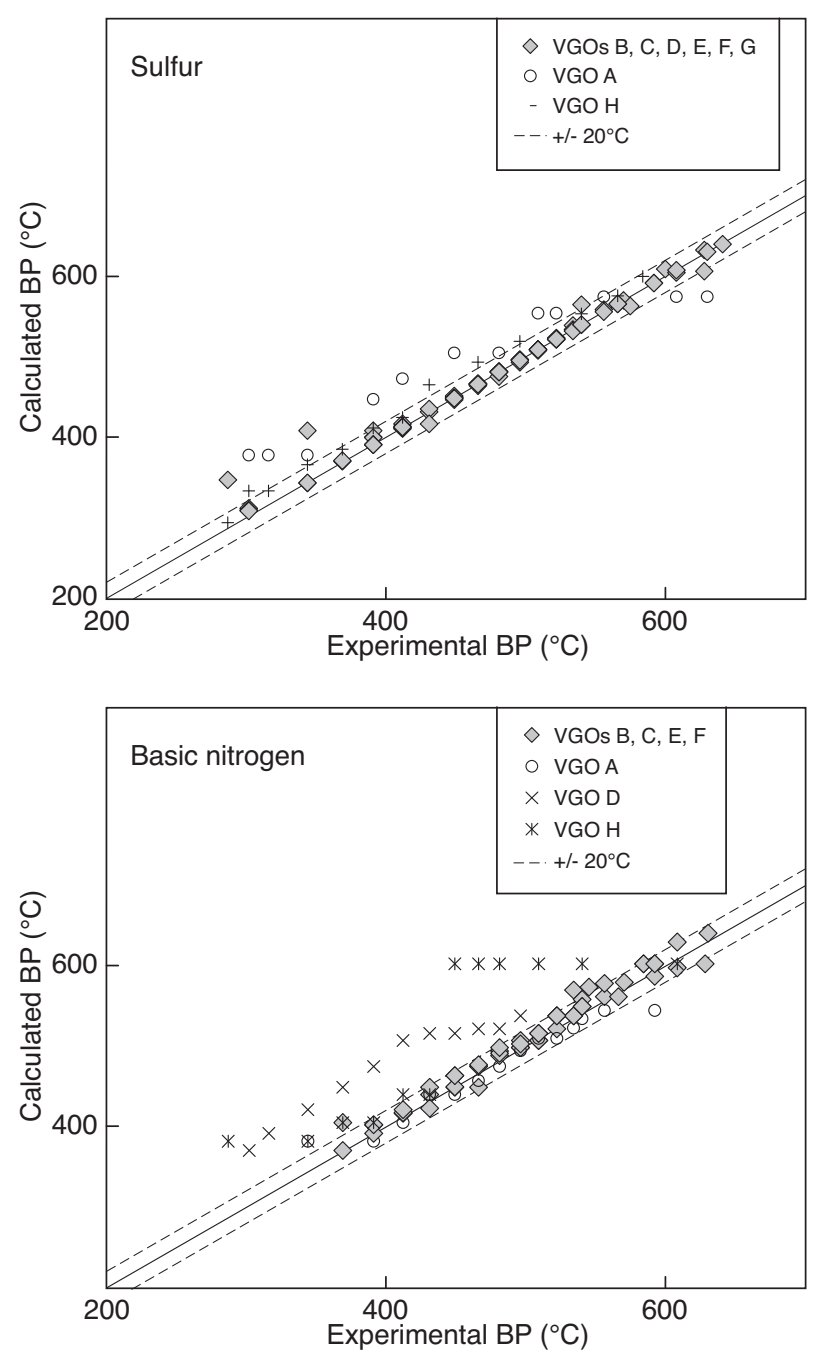

Subsequently, the molar fraction of each molecule of the equimolar set is adjusted using an "information entropy maximization" algorithm. In this method, the distribution of the compounds in the set is modified to match the constraints (i.e. the analytical data of the petroleum cut). The two outlined methods were applied to both the Vacuum Gas Oils and their hydrotreated products $\left(375^{\circ} \mathrm{C}+\right)$ in order to get a molecular description of these petroleum fractions.

Stochastic reconstruction is a far more time-consuming algorithm than the information entropy maximization method. So, in this study, we have chosen to generate a set of 10000 molecules by stochastic reconstruction using the experimental data of the VGOs B and C. These samples were selected because they exhibit average global properties when compared to other Vacuum Gas Oils. The equimolar mixture resulting from stochastic reconstruction of VGOs $\mathrm{B}$ and $\mathrm{C}$
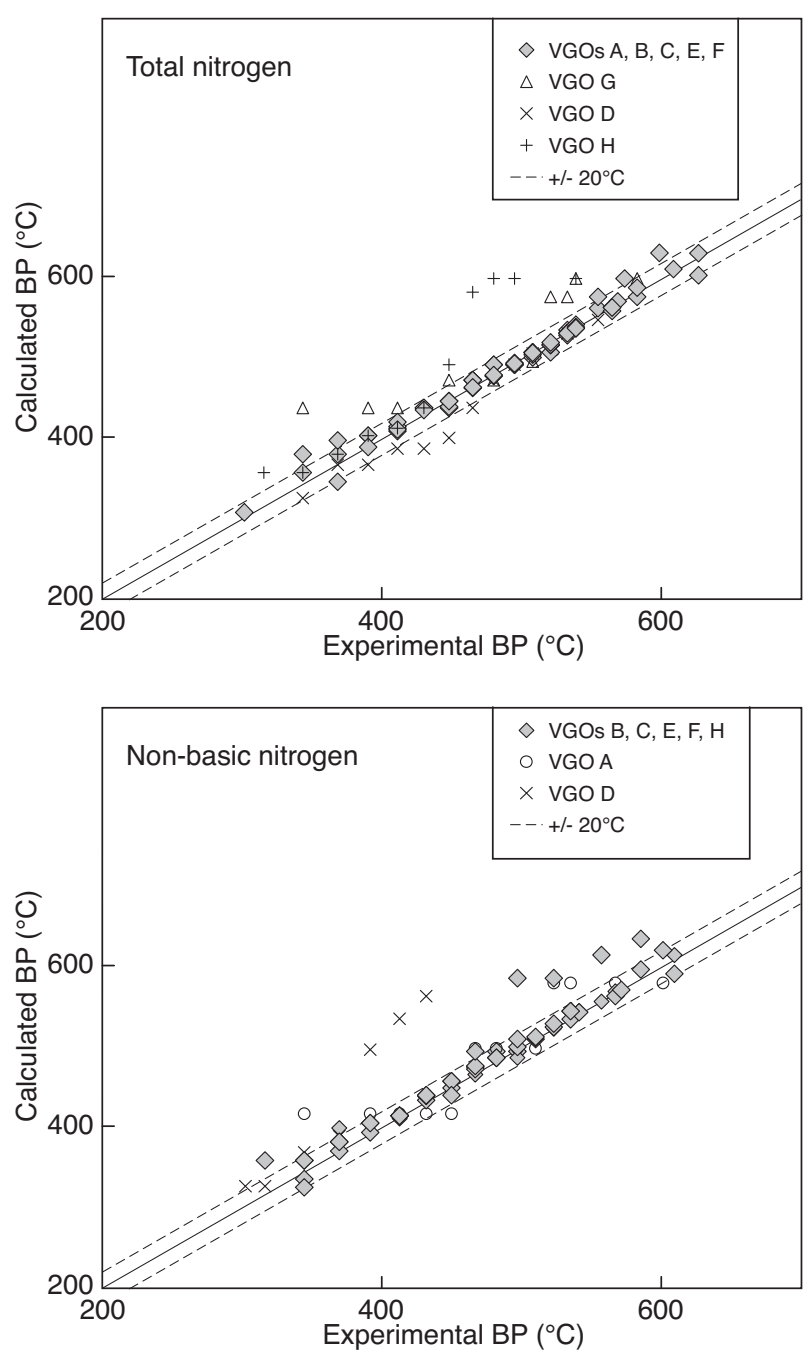

Figure 6

Molecular reconstruction parity diagrams of the sulfur, nitrogen, non-basic nitrogen and basic nitrogen simulated distillation data of Vacuum Gas Oil feedstocks. 


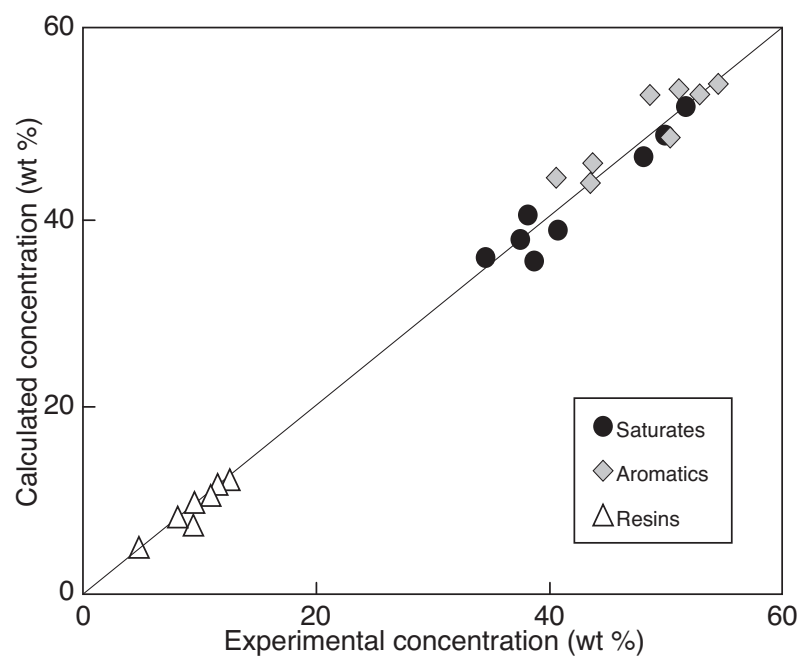

Figure 7

Molecular reconstruction parity diagram of the saturates, aromatics and resins contents in Vacuum Gas Oil feedstocks.

was considered to be a representative basis of the chemical compounds that are usually present in Vacuum Gas Oil fractions. The information entropy maximization algorithm was then applied to this representative set for each VGO A to K individually, i.e. the molar fractions of the set were adjusted using the experimental data of the studied sample.

Standard analyses (elementary analysis, density, etc.) as well as sulfur and nitrogen (total, basic and non-basic nitrogen) simulated distillation curves were used as experimental data to fit the molecular reconstruction of Vacuum Gas Oils and hydrotreated products. In order to evaluate the quality of the molecular reconstruction approach, the properties of the molecule sets were compared to the analytical data of the industrial cuts. Some comparisons of calculated versus experimental data are discussed in this paper.

It was demonstrated previously (Sect. 2.1) that GC-AED/ NCD analysis of Vacuum Gas Oils and their "Basic" and "Non-basic" fractions provide the boiling point distribution of the heteroatomic-containing compounds of Vacuum Gas Oils. This experimental information was used as input data in the molecular reconstruction algorithm. Figure 6 shows that the boiling points of sulfur and nitrogen compounds are well estimated by molecular reconstruction when compared to the experimental data, except for VGO H. This sample is considered as an atypical Vacuum Gas Oil since it has a high content of low boiling point sulfur and nitrogen compounds; furthermore, its total and basic nitrogen contents are particularly high (3765 and $1071 \mathrm{wt}$ ppm N, respectively).

A silica-phase chromatographic technique is generally used to analyze heavy petroleum fractions. This separation technique provides the contents of Saturates, Aromatics and Resins (SAR) that are present in Vacuum Gas Oils. Figure 7 represents the calculated versus experimental data for each class of compounds. It can be concluded that saturates, aromatics and resins in Vacuum Gas Oils are well predicted by molecular reconstruction.

The molecular reconstruction algorithm was also applied to represent the hydrotreated VGO fractions. The elementary simulated distillations of sulfur and nitrogen-containing compounds from hydrotreated VGOs are very well estimated by molecular reconstruction (Fig. 8). There is only a small variation between experimental and calculated temperatures for the beginning and the end of the distillation curves ( 0.5 and $99.5 \mathrm{wt} \%$ boiling points, respectively).
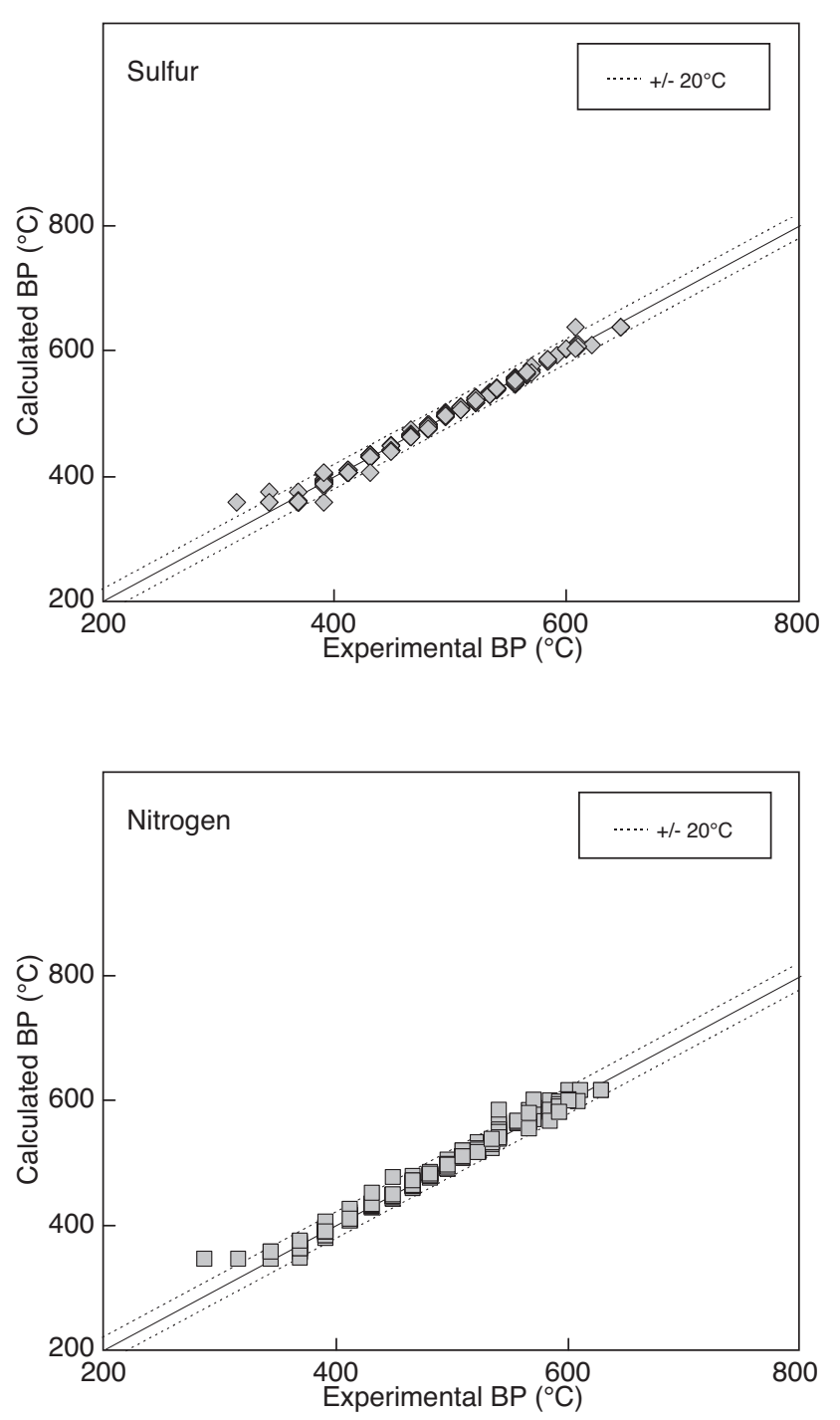

Figure 8

Molecular reconstruction parity diagrams of the sulfur and nitrogen simulated distillation data of hydrotreated VGO fractions. 

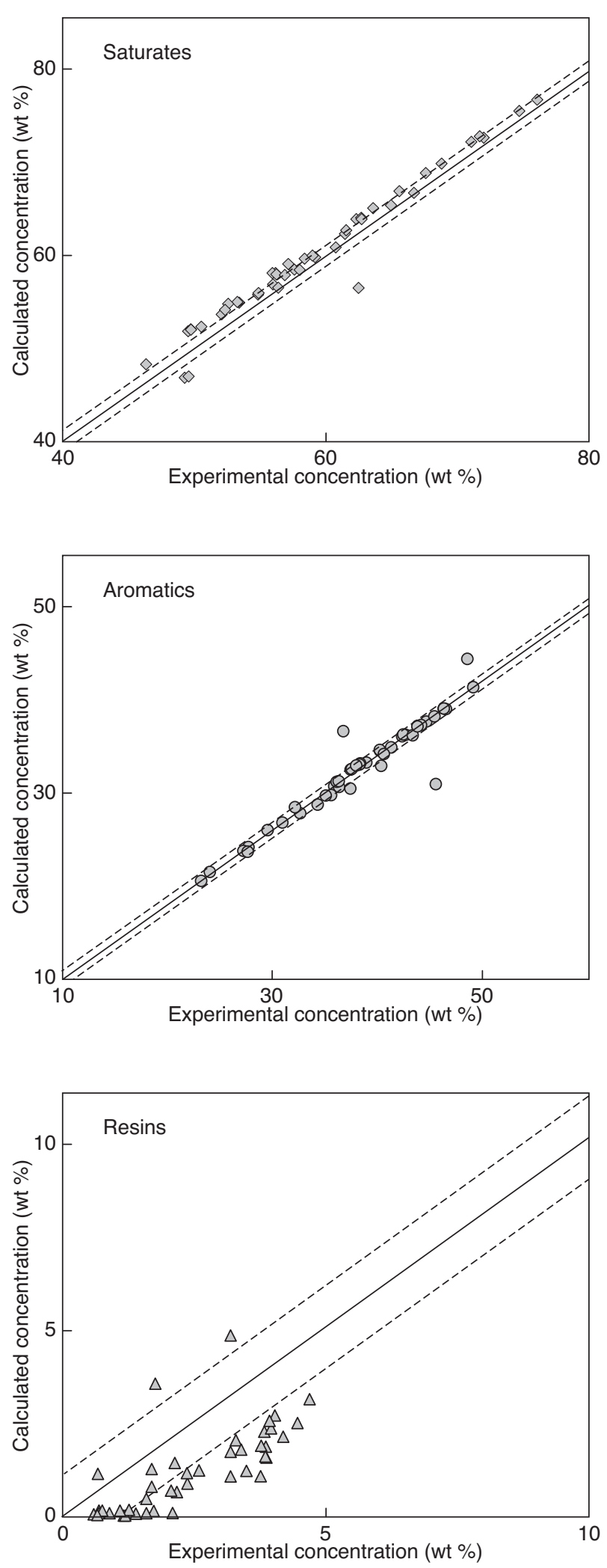

Figure 9

Molecular reconstruction parity diagrams of the saturates, aromatics and resins contents in hydrotreated VGO fractions.
Concerning the SAR analyses of hydrotreated VGOs, the calculated contents of saturates and aromatics obtained by molecular reconstruction are in good agreement with experimental data (Fig. 9). However, the estimation of resins contents is more difficult and the criteria used for the distinction between aromatics and resins in the molecular reconstruction algorithm should be optimized specifically for hydrotreated VGO fractions.

As explained above, the molecular reconstruction algorithm used in this study is a two-step algorithm that couples the stochastic reconstruction and information entropy maximization approaches. This numerical method enables the molecular description of Vacuum Gas Oils and hydrotreated VGOs by means of mixtures of saturates, aromatics, sulfur and nitrogen-containing compounds. In most of the cases, the global properties of the Vacuum Gas Oil fractions are well estimated by molecular reconstruction. Nevertheless, the performances of this method could be further improved by using more accurate group contribution methods to estimate the boiling point temperatures of heteroatomic compounds more precisely. Larger sets of molecules could also be constructed from various Vacuum Gas Oil cuts to generate a larger and more diversified set of compounds during the stochastic reconstruction step.

\subsection{Kinetic Modeling of Vacuum Gas Oil Hydrotreating}

Heavy petroleum cuts such as Vacuum Gas Oils are converted into valuable gasoline and diesel fractions to fulfill the worldwide increasing fuel demand. This transformation is performed by refinery processes such as fluid catalytic cracking or hydrocracking. Hydrotreating of Vacuum Gas Oils is required prior to these conversion steps in order to remove the nitrogen species that are catalyst inhibitors. Nevertheless, nitrogen compounds exhibit different reactivities depending on their chemical structure: basic acridine derivates are well-known strong catalyst inhibitors and competitors towards other species, while non-basic carbazole derivates have a refractory behavior. Therefore, kinetic modeling of hydrotreating is essential to understand and predict the performances of hydrodearomatization (HDA), hydrodesulfurization (HDS) and hydrodenitrogenation (HDN) reactions. Several literature works have studied the behavior, mechanisms and kinetics of hydrotreating of industrial gasolines, diesel cuts [27-36] as well as Vacuum Gas Oils [36-38]. However, concerning VGOs, no detailed kinetic model has been reported in literature. In this work, an innovative approach coupling molecular reconstruction of Vacuum Gas Oils and kinetic modeling of hydrotreating reactions is proposed.

For this purpose, Vacuum Gas Oils and hydrotreated products were represented as mixtures of molecules by molecular reconstruction. For each petroleum cut, molecules were 


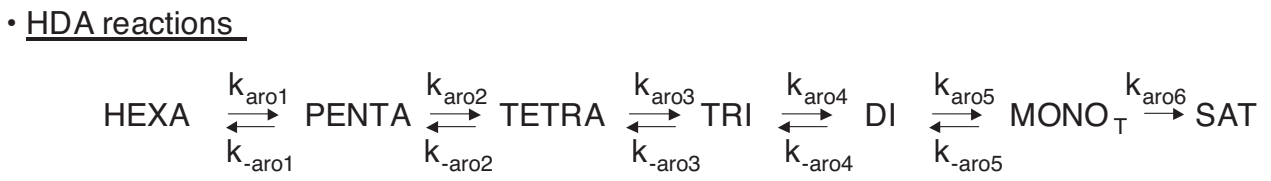

- HDS reactions

Polydbt $\underset{\mathrm{k}_{-\mathrm{S} 1}}{\stackrel{\mathrm{k}_{\mathrm{S} 1}}{\longrightarrow}}$ Sulfur $\stackrel{\mathrm{k}_{\mathrm{S} 2}}{\longrightarrow}$ MONO $_{\sigma} \stackrel{\mathrm{k}_{\text {aro7 }}}{\longrightarrow} \mathrm{SAT}+\mathrm{H}_{2} \mathrm{~S}$

- $\underline{\text { HDN reactions }}$

Non-basic nitrogen $\stackrel{\mathrm{k}_{\mathrm{N} 1}}{\rightleftarrows}$ Basic nitrogen $\stackrel{\mathrm{k}_{\mathrm{N} 2}}{\longrightarrow} \mathrm{SAT}+\mathrm{NH}_{3}$

Figure 10

General scheme of kinetic modeling of VGO hydrotreating.

lumped into chemical families according to their hydrotreatment reactivity and these lumps were used as the kinetic model inputs. Six aromatic, two sulfur, two nitrogen and one saturate lumps were generated from the molecular reconstruction data. Aromatic compounds were lumped according to their number of benzene rings. Molecules having six or more aromatic rings were grouped into a "Hexa" lump. Sulfur containing-compounds were divided into two classes: compounds having a thiophenic structure and at least one benzene ring were lumped into a "Polydbt" family, while other sulfur compounds (thiophenes and sulfides) were classified into a "Sulfur" lump. With respect to nitrogen-containing compounds, carbazole derivates were lumped in a "NonBasic Nitrogen" family, while acridine derivates and amines were grouped in a "Basic Nitrogen" lump.

A kinetic model based on a Langmuir-Hinshelwood mechanism was developed with these lumps. It takes into account two different types of catalytic sites: one for hydrogenation $(\tau)$ reactions and one for hydrogenolysis $(\sigma)$ reactions. Figure 10 illustrates the general kinetic modeling scheme for Vacuum Gas Oil hydrotreatment. Aromatic lumps are transformed by successive and reversible hydrogenation/dehydrogenation reactions. Hydrodesulfurization reactions involve hydrogenation of the "Polydbt" lump into the "Sulfur" family, which is then converted into the "Monoaromatic" family by hydrogenolysis reactions. Nonbasic nitrogen compounds are first transformed into the "Basic Nitrogen" lump by hydrogenation of the aromatic rings of the carbazole derivates. Hydrogenolysis of basic nitrogen-containing molecules implies the formation of saturates and the removal of ammonia.

In this work, it is considered that the first hydrogen addition to a cycle is the rate-determining step for the hydrogenation of aromatic cycles. These hydrogenation reactions occur on the sites. Regarding the hydrogenation of mono aromatics in saturates, it is considered that these reactions occur on both catalytic sites, and are irreversible. Concerning the hydrotreatment of cyclic molecules containing sulfur or nitrogen, the rate-determining step is also considered to be the first hydrogenation of the cycle. Hydrodesulfurization and hydrodenitrogenation reactions are also considered to be irreversible.

The experimental tests were conducted in an isothermal and isobaric fixed-bed hydroprocessing reactor. It is considered that this reactor operates in a pure piston flow mode and that the vapor-liquid equilibrium is established throughout the reactor, without any diffusional limitations. The steady state reactor model is therefore a system of ordinary differential equations that calculate the material balances of each species involved in the reactor. The calculation of the vapor-liquid equilibria is also integrated in the reactor simulator, using a Grayson-Streed model. This set of equations is solved numerically using the LSODE computer algorithm.

In order to identify the parameters of the kinetic model, this reactor simulator was plugged into an optimizer with a Levenberg-Marquardt algorithm. The parameters were obtained by minimizing the weighted sum of the squares of the differences between the experimental data obtained through molecular reconstruction and the simulated results. The experimental data used in this study resulted from hydrotreating of industrial VGOs over a NiMoS/ $/ \mathrm{Al}_{2} \mathrm{O}_{3}$ catalyst at $375-400^{\circ} \mathrm{C}, 40-140$ bar (total pressure) with a contact time of $0.5-2$ hours. In most cases, heavy fractions $\left(375^{\circ} \mathrm{C}+\right)$ represent around $85 \mathrm{wt} \%$ of the hydrotreated VGO products that were investigated in this study. So it was assumed that the hydrotreatment operating conditions used in this work 


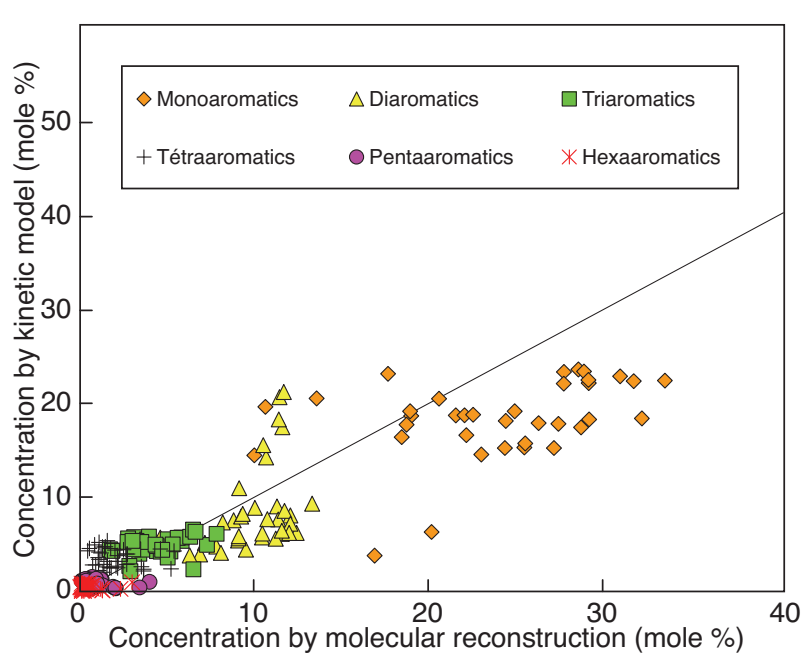

Figure 11

Kinetic model parity diagram for the aromatic lumps at the outlet of the reactor.

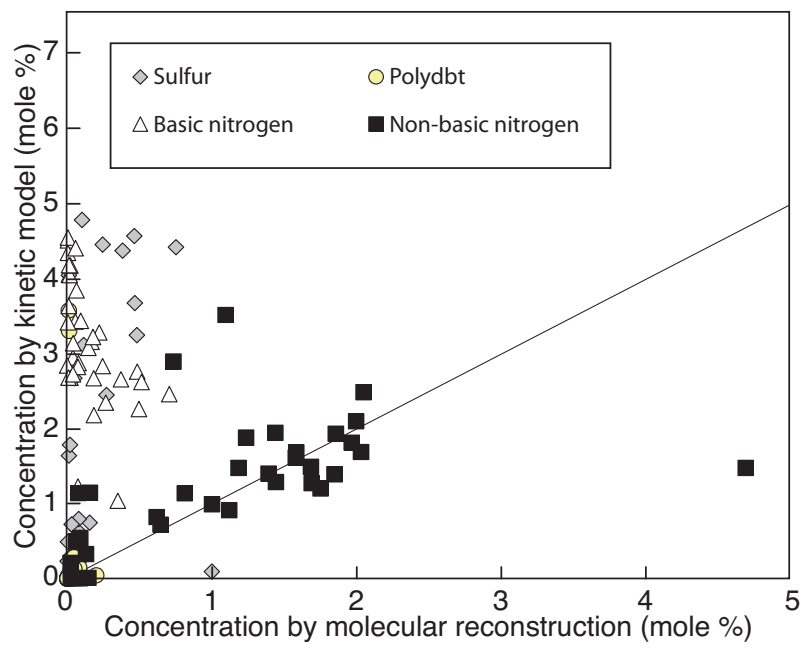

Figure 12

Kinetic model parity diagram of the sulfur and nitrogen lumps at the outlet of the reactor. lead to very few cracking reactions and that these heavy fractions can be considered as representative to the whole hydrotreated products. Therefore, for this part of our work, only the resulting $375^{\circ} \mathrm{C}+$ fractions of hydrotreated VGO products were taken into account in this model.

Figure 11 represents the concentration of the aromatic lumps calculated by the kinetic model versus the experimental data. The results show that the concentrations of the aromatic families are well estimated by the kinetic model. However, the concentrations of the "Mono" lump are somewhat lower than the experimental concentrations. During hydrotreatment, polyaromatic compounds are mainly converted into monoaromatics, which are essentially present in the light and middistillate fractions of the hydrotreated products. Therefore, further work will take into account the $375^{\circ} \mathrm{C}$ - fractions in the model in order to improve the estimated performances of the "Mono" lump.

Figure 12 illustrates the comparison between calculated and experimental sulfur and nitrogen concentrations of the hydrotreated Vacuum Gas Oils. A good agreement between experimental and calculated data is obtained for the nonbasic nitrogen-containing compounds. However, the concentrations of the other heteroatomic families are not well estimated. These results may be explained by the fact that the chemical families contain compounds of different reactivities. First, the kinetic model should distinguish sulfur compounds produced after the hydrogenation of the "Polydbt" lump and those obtained from the thiophenes and sulfides, which are much more reactive. In a similar manner, the "Basic Nitrogen" lump should be separated in two families: a family containing hydrogenated carbazole derivates and another composed of amines and acridine derivates. A further improvement is to achieve better performances in molecular reconstruction since the quality of the kinetic modeling is directly related to the molecular reconstruction data. Using more accurate group contribution methods to calculate boiling points and generating larger and more diversified molecule sets would certainly contribute to obtain better results for the kinetic modeling of Vacuum Gas Oil hydrotreating reactions.

\section{CONCLUSION}

This work presents new analytical tools to characterize the chemical families in Vacuum Gas Oil fractions as well as a kinetic model for VGO hydrotreatment based on molecular reconstruction. Concerning the analytical tools, two main developments are presented. First, a new GC-AED/NCD hyphenated technique coupling two specific GC detectors was developed to determine the content of sulfur and nitrogen containing-compounds by increasing boiling point. This technique was applied to characterize Vacuum Gas Oil feeds and their hydrotreated products. The second technique achieves the separation of basic and non-basic nitrogen-containing compounds of Vacuum Gas Oils. This separation is based on a simple but innovative extraction method carried out with an ion-exchange resin. After separation, the repartition of basic and non-basic nitrogen compounds in these heavy petroleum cuts is available.

In order to obtain the input data for the kinetic model, a molecular reconstruction approach was developed. It enables 
to describe the molecular composition of Vacuum Gas Oils and hydrotreated products. Detailed sets of saturates, aromatics, sulfur and nitrogen-containing compounds are accurately simulated via this approach. The molecular reconstruction data were then used to generate chemical families according to the reactivity of the compounds during hydrotreating. A first version of a kinetic model of Vacuum Gas Oil hydrotreatment that takes into account hydrodearomatization, hydrodesulfurization and hydrodenitrogenation reactions was developed. The concentrations of the aromatic families are well predicted. Some progress concerning the prediction of HDN and HDS is still needed and will be attempted from improvements such as a more detailed distinction of different lumps of sulfur and nitrogen-containing compounds as well as the improvement of the molecular reconstruction results.

\section{ACKNOWLEDGMENTS}

The authors would like to thank D. Hudebine, J. Verstraete, P. Schnongs from IFP Energies nouvelles for their important contribution to this work.

\section{REFERENCES}

1 Revellin N., Dulot H., López-García C., Baco F., Jose J. (2005) Specific Nitrogen Boiling Point Profiles of Vacuum Gasoils, Energ. Fuel. 19, 6, 2438-2444.

2 Revellin N. (2006) Modélisation cinétique de l'hydrotraitement des distillats sous vide, Thèse, École Normale Supérieure de Lyon.

3 Dorbon M., Schmitter J.M., Garrigues P., Igniatadis I., Ewald M., Arpino P., Guiochon G. (1984) Distribution of carbazole derivatives in petroleum, Org. Geochem . 7, 111-120.

4 Del Bianco A., Zaninelli M., Girardi E. (1987) Characterization scheme of nitrogen bases in coal-derived liquids, Fuel 66, 55-57.

5 Hsu C.S., Qian K., Robbins W.K. (1994) Nitrogen speciation of polar petroleum compounds by compound class separation and on-line liquid chromatography-mass spectrometry (LC-MS), J. High Resolution Chromatography 17, 271-27.

6 Merdrignac I. (1997) Composition des structures azotées dans les pétroles. Implication pour leur réactivité au cours des procédés d'hydrodésazotation, Thèse, Université Louis Pasteur.

7 Merdrignac I., Behar F., Albrecht P., Briot P., Vandenbroucke M. (1998) Quantitative extraction nitrogen compounds in oils: atomic balance and molecular composition, Energ. Fuel. 12, 1342-1355.

8 Whitehurst D.D., Knudsen K., Wiwel P., Zeuthen P., Topsoe H. (2000) The influence of trace amounts of nitrogen compounds on the achievement of future sulfur specifications in diesel fuels - part 1: HDS inhibition studies with model N-compounds, 219th National Meeting American Chemical Society, March 2631, pp. 692-696.

9 Laredo G., Leyva S., Alvarez R., Mares M.T., Castillo J., Cano J.L. (2002) Nitrogen compounds characterization in atmospheric gas oil and light cycle oil from a blend of Mexican crudes, Fuel 81, 1341-1350.

10 Briker Y., Ring Z., Iacchelli A., McLean N. (2003) Miniaturized method for separation and quantification of nitrogen species in petroleum distillates, Fuel 82, 1621-1631.
11 Mao J., Pacheco C., Traficante D., Rosen W. (1995) Identification and characterization of nitrogen compounds in Brazilian diesel oil by particle beam LC-MS, Fuel 74, 6, 880-887.

12 Que G., Li N. (1998) Separation and characterization of nitrogen compounds in petroleum vacuum residues, 215th National Meeting, American Chemical Society, Dallas, TX, March 29-April 3,pp. 177-181.

13 Green J.B., Hoff R.J., Woodward P.W., Stevens L.L. (1984) Separation of liquid fossil fuels into acid, base and neutral concentrates, Fuel 63, 1290-1300.

14 Conceiçao Oliveira E., Vaz de Campos M.C., Sant'Ana Lopes A., Rodrigues Vale M.G., Caramao E.B. (2004) Ion-exchange resins in the isolation of nitrogen compounds from petroleum residues, J. Chromatogr. A 1027, 171-177.

15 Sasaki M., Yokono T., Satou M., Sanada Y. (1991) Fractionation of coal pitch with iodine, Energ. Fuel. 5, 122-125.

16 Nwadinigwe C.A., Maduka M.C. (1993) A quantitative assessment of the classes of nitrogenous compounds in light crudes, Fuel 72, 8, 1139-1142.

17 Zhang H., Que G., Li P. (1998) Isolation of basic nitrogen compounds from lubricating base oil with complex formation method, Symposium on Chemical Analysis of Crude Oils for Optimizing Refinery Yields and Economics, Am. Chem. Soc. 3, 182-184.

18 Mushrush G., Beal E., Hardy D., Hughes J. (1999) Nitrogen compound distribution in middle distillate fuels from petroleum, oil shale, and tar sand sources, Fuel Process. Technol. 61, 197-210.

19 Verstraete J., Revellin N., Dulot H., Hudebine D. (2004) Molecular reconstruction of vacuum gasoils, Prep. Am. Chem. Soc. Div. Fuel Chem. 49, 1, 20-21.

20 Neurock M., Nigam A., Trauth D., Klein M.T. (1994) Molecular representation of complex hydrocarbon feedstocks through efficient characterization and stochastic algorithms, Chem. Eng. Sci. 49, 4153-4177.

21 Trauth D., Stark S., Petti T., Neurock M., Klein M.T. (1994) Representation of the molecular structure of petroleum resid through characterization and Monte Carlo modeling, Energ. Fuel. 8, 576-580.

22 Khorasheh F., Khaledi R., Gray M.R. (1998) Computer generation of representative molecules for heavy hydrocarbon mixtures, Fuel 77, 4, 241.

23 Hudebine D., Vera C., Wahl F., Verstraete J. (2002) Molecular Representation of Hydrocarbon Mixtures from Overall Petroleum Analyses, AIChE Spring Meeting, New Orleans, LA, March 10-14, Paper 27a.

24 Hudebine D. (2003) Reconstruction moléculaire de coupes pétrolières, Thèse, École Normale Supérieure de Lyon.

25 Hudebine D., Verstraete J. (2004) Molecular reconstruction of LCO gasoils from overall petroleum analyses, Chem. Eng. Sci. $\mathbf{5 9}, 22$.

26 Ha Z., Ring Z., Liu S. (2005) Derivation of molecular representations of middle distillates, Energ. Fuel. 19, 2378-2393.

27 Magne-Drisch J. (1995) Cinétique des réactions d'hydrotraitement de distillats par décomposition en familles et par coupes étroites, Thèse, Université Pierre et Marie Curie Paris VI.

28 Bonnardot J. (1998) Modélisation cinétique des réactions d'hydrotraitement par regroupement en familles chimiques, Thèse, Université Claude Bernard Lyon I.

29 López-García C. (2000) Analyse de la réactivité des composés soufrés dans les coupes pétrolières : cinétique et modélisation de l'hydrotraitement, Thèse, Université Claude Bernard Lyon 1. 
30 Shin S., Sakanishi K., Mochida I. (2000) Identification and reactivity of nitrogen molecular species in gas oils, Energ. Fuel. 14, 539-544.

31 Zeuthen P., Stolze P., Pedersen U.B. (1987) Kinetics for simultaneous HDS, HDN and hydrogenation model reactions on a $\mathrm{CoMo} / \mathrm{Al}_{2} \mathrm{O}_{3}$ catalyst, Bulletin Société Chimie Belge 96, 11 , 985-995.

32 Sumbogo S., Yang H., Choi K.H., Korai Y., Mochida I. (2003) Influences of nitrogen species on the hydrodesulfurization reactivity of a gas oil over sulfide catalysts of variable activity, Appl. Catal. A 252, 331-346.

33 Yang H., Chen J., Fairbridge C., Briker Y., Zhu Y.J., Ring Z. (2004) Inhibition of nitrogen compounds on the hydrodesulfurization of substitued dibenzothiophenes in light cycle oil, Fuel Process. Technol. 85, 1415-1429.

34 Owusu-Boakye A., Dalai A.K., Ferdous D., Adjaye J. (2005) Experimental and kinetic studies of aromatic hydrogenation, hydrodesulfurization, and hydrodenitrogenation of light gas oils derived from Athabasca bitumen, Ind. Eng. Chem. Res. 44, 7935-7944.
35 Rabarihoela V. (2005) Mise au point de nouveaux carburants propres: hydrodésulfuration intime des gazoles en présence de molécules réfractaires modèles, Thèse, Université de Poitiers.

36 Sau M., Basak K., Manna U., Santra M., Prakash Verma R. (2005) Effects of organic nitrogen compounds on hydrotreating and hydrocracking reactions, Catal. Today 109, 112-119.

37 Bej S.K., Dalai A.K., Adjaye J. (2001) Comparison of hydrodenitrogenation of basic and nonbasic nitrogen compounds present in oil sands derived heavy gas oil, Energ. Fuel. 15, 377-383.

38 Ferdous D., Dalai A.K., Adjaye J. (2006) Hydrodenitrogenation and hydrodesulfurization of heavy gas oil using $\mathrm{NiMo} / \mathrm{Al}_{2} \mathrm{O}_{3}$ catalyst containing boron: experimental and kinetic studies, Ind. Eng. Chem. Res. 45, 544-552.

Final manuscript received in January 2010 Published online in October 2010 